\title{
Quantifying the out-of-plane response of unreinforced masonry walls subjected to relative support motion
}

\author{
Michele Godio, Katrin Beyer \\ Laboratory of Earthquake Engineering and Structural Dynamics (EESD), School of Architecture, Civil and Environmental Engineering \\ (ENAC), Ecole Polytechnique Fédérale de Lausanne (EPFL), EPFL ENAC IIC EESD, GC B2 495, Station 18, CH-1015 Lausanne, \\ Switzerland \\ michele.godio@epfl.ch, bttps://orcid.org/0000-0002-9586-8667 \\ katrin.beyer@epfl.ch,bttps://orcid.org/0000-0002-6883-5157
}

ABSTRACT. The supports of out-of-plane loaded unreinforced masonry walls in buildings are subjected to a motion that is filtered and amplified by the building structure and, in some cases, can be significantly different from the ground motion. Moreover, because these walls span one or several storeys, their top and bottom supports are subjected to motions that differ in phase and amplitude. In state-of-the-art assessment procedures for the out-of-plane stability of masonry walls any effect of a relative support motion is neglected. The objective of this paper is to study the effect of the relative support motion on the response of out-of-plane loaded vertically-spanning unreinforced masonry walls. The acceleration capacity of the walls is investigated by means of a discrete element model representative of different wall configurations. A set of ground motions covering a wide range of peak ground acceleration and peak ground displacement is used as input to the simulations. The relative motion between the wall supports is included in the model in a systematic way: firstly, through a motion that is non-synchronous but of equal amplitude; secondly, through a motion that is synchronous but of different amplitude. The effect of the relative support motion is studied on different wall configurations where the elastic modulus of masonry, the wall height-to-thickness ratio, the wall effective thickness and the overburden at the top wall are varied. The study shows that, because of the relative support motion, the acceleration capacity of the walls can drop by $20 \%$ and, in the cases where the overburden is high, by more than $50 \%$.

KEYWORDs. Masonry; Out-of-plane loading; Discrete elements; Incremental dynamic analysis; Support motion; Out-of-phase.

\section{OPEN ACCESS}

Citation: Godio, M., Beyer, K., Quantifying the out-of-plane response of unreinforced masonry walls subjected to relative support motion, Frattura ed Integrità Strutturale, 50 (2019) 194-208.

Received: 05.06.2019

Accepted: 31.07.2019

Published: 01.10.2019

Copyright: (C) 2019 This is an open access article under the terms of the CC-BY 4.0, which permits unrestricted use, distribution, and reproduction in any medium, provided the original author and source are credited. 


\section{INTRODUCTION}

$\mathrm{U}$ nreinforced masonry (URM) walls are very vulnerable to the out-of-plane actions, even more so at the higher levels of a building where the accelerations are large and the walls relatively slender [1]. The supports of out-of-plane loaded masonry walls in a building are subjected to a motion that is filtered and amplified by the building structure and, in some cases, can be significantly different from the ground motion. Moreover, because these walls span one or several storeys, their top and bottom supports are subjected to motions that differ in phase and amplitude. Relative support motion is reportedly due to two factors affecting the path of the seismic action from the ground to the walls located at the upper storeys of a building [2]: first, the diaphragm response, notably the in-plane or membrane flexibility of the diaphragm, see e.g. [3,4], and, second, the filtering and amplifying effect due to the building structure and, in particular, the shear walls.

The performance of unreinforced masonry walls subjected to out-of-plane support motion including these two factors has been the topic of only few numerical studies so far. Landi et al. [5] investigated the response of pinned-clamped walls undergoing vertical bending. The walls were modelled as assemblies of two axially-loaded rigid macro-blocks fully separated by a crack at a certain wall height and laterally restrained at the top by a spring. The wall motion was described by a Lagrangian system of equations based on two degrees of freedom and integrated on a series of gaussian impulses and natural records. Penner et al. [6] performed a parametric study on pinned-clamped vertically-spanning walls by using the software Working Model 2D [7]. The study extended the one by Sharif et al. [8], who analysed two rigid macro-blocks subjected to equal input support motion, to two rigid macro-blocks subjected to relative support motion. This was achieved by connecting two lateral springs to the macro-block ends. The study included variations of the spring stiffnesses, wall thickness and slenderness and axial load magnitude and eccentricity. Code-based records were used as input to the numerical model. Derakhshan et al. [9] investigated the response of walls with pinned-pinned elastically-restrained supports. The wall response was captured by means of a tri-linear force-displacement model built upon a two-rigid-macro-block description. With respect to the two above-mentioned works [5,6], in this work the filtering action played by the structure was considered in the implementation of the input ground motions. As a result of the adopted filtering process, the input code-compatible records applied to the wall supports had a dominant period close to that of the building [9]. The out-of-plane response of URM walls was also studied by Tondelli et al [10], who included as input to the out-of-plane wall support motion not only the effect of filtering due to the mixed unreinforced masonry - reinforced concrete wall structure but also the effect of rocking and therefore elongation of adjacent in-plane loaded URM walls on the top restraint of the out-of-plane loaded wall. Both effects were experimentally observed [11] and simulated by means of the software UDEC 6.0 [12], where each brick row was modelled as a discrete rigid block.

The above-mentioned numerical studies all show that URM walls appear to be more vulnerable when they are subjected to relative out-of-plane support motions $[5,6,9,10]$. Providing some degree of flexibility to the wall supports by means of springs, which allows mimicking the situation in which the supports do not move simultaneously, leads in fact to a displacement demand that is higher than that of a wall with 'fixed' or highly stiff supports. While a wall with fixed supports collapses because of the excessive mid-height displacement [13-15], a wall with flexible supports can also collapse due to the excessive support displacement $[9,16]$. Furthermore, the more the supports are flexible and have a different degree of flexibility, the higher can be the difference between the top and the bottom motions and the more vulnerable becomes the wall $[6,16]$. In the case of a very flexible top support, the upper macro-block behaves similarly to a parapet wall elastically restrained at the top and rocking on the lower macro-block, which, in turn, rocks on the fixed bottom support. In this situation, the support motion can give rise to a deformation pattern that is characterized by both macro-blocks rocking in the same direction, see e.g. [17]. This pattern is unfavourable when compared to the one experienced by a wall spanning vertically on fixed supports, since it results in a reduced wall force capacity [18] and displacement capacity [9]. The wall acceleration capacity consequently reduces. Depending on the wall configurations, flexible supports were found to reduce the wall capacity by up to 1.3 times [6], but a systematic study quantifying the vulnerability of out-of-plane walls subjected to the relative support motion based on the input motion characteristics is missing.

In the above-mentioned studies, the URM walls are modelled as vertical strips undergoing vertical one-way bending. Such wall layout is simple yet representative of many wall configurations that are vulnerable to out-of-plane loading. During earthquakes, the effectiveness of wall side restraints, which would cause two-way bending, could in fact decrease, e.g. due to the weakening of the wall corners, which finally comes to trigger vertically-spanning overturning mechanisms. Such wall configurations have also been tested on shake tables. Among these tests, $[15,16,19,20]$ include observations on the relative motion of the wall supports. When subjected to relative support motions the walls exhibit an acceleration profile varying piecewise linearly along the wall height [15]. Furthermore, the motion of the top and bottom connections may not necessarily be in-phase $[16,19,20]$. These are certainly two sources of wall collapse that are, nonetheless, difficult to predict and quantify 
[15]. Moreover, test results [15] have shown a significant decrease in the initial lateral wall stiffness when cracking occurs. The stiffness also decreases through subsequent tests due to damage, that is, even if no new major cracks appear. The influence of the elastic modulus of masonry was, however, not included in previous numerical studies $[5,6,9,10]$ and needs therefore to be investigated in a more systematic way.

The objective of the here presented study is to quantify the vulnerability of walls subjected to the relative support motion by investigating the influence of the two fundamental input motion characteristics, which are (i) the relative amplitude and (ii) the phase shift between the top and bottom support motions. The numerical modelling of rocking masonry structures is a challenging task and many numerical modelling techniques based on e.g. finite element [21-23], discrete element [2428], applied element [29,30] and rigid-block models [31] have been put forward in the recent years. In this study, the URM walls are modelled by means of a discrete element model, which was already validated and employed in a previous work on walls with fixed support motions [32]. Unlike the models used in previous numerical studies analysing URM walls under relative support motions $[4,5,8]$ - except [10] - the here presented study makes no assumption on the height at which the macroscopic crack forms dividing the one-way spanning wall into a lower and an upper rocking body. This more versatile modelling approach allows some essential features of the out-of-plane behaviour of URM walls to be captured, namely, the opening/closure of the interfaces following the impacts and the change in height of the macroscopic crack during the shake due to the activation of 'modes' of rocking other than the two-macro-block mechanisms usually investigated [15]. Relative support motions are generated from a suite of natural records. Starting from these records, support motions are derived by changing, on the one hand, the phase shift, and, on the other hand, the relative amplitude. This is done by applying appropriate signal processing techniques. The strategy followed in this paper to produce records with relative amplitude formalises and extends the one already adapted by Tondelli et al. [10]. In this paper, this strategy is applied for different wall configurations and, as a novelty, a strategy to produce out-of-phase motions is introduced. The resulting support motions are not necessary representative of the real floor motions, as these latter are usually amplified around the building frequency $[2,9,33,34]$. The reason of using synthetically-generated instead of experimentally-derived floor motions is that the former allows us examining a wide range of configurations controlling precisely the input motion characteristics. The vulnerability of the walls against relative support motions is quantified for different wall configurations through fragility curves. A parametric study investigates the acceleration capacity and the failure mechanisms of URM walls in which the masonry elastic modulus, wall height-to-thickness ratio, wall effective thickness and applied axial load (overburden) are varied. Godio and Beyer [32] carried out a parametric study on the same wall configurations and records, but for wall with identical support motions.

\section{RESPONSE OF URM WALLS UNDER RELATIVE SUPPORT MOTION}

$\mathrm{O}$ bservations from shake table test show that uncracked URM walls undergo a uniform or a linearly varying acceleration profile along their height, depending on whether the input motions at the top and bottom of the wall are the same, i.e. have equivalent amplitude and are in-phase, or not [15]. When the walls are cracked, the acceleration profile becomes piece-wise linear between the cracks [15], and, for the general case in which the supports undergo relative motion, consists of three components (Fig. 1): (a) a constant one, generated by the overall support motion; (b) a linear one, provided by the relative motion between the top and bottom supports, as a result, for instance, of the diaphragm flexibility; (c) a piece-wise linear one, engendered by the inertia of the macro-blocks separated by the cracked middle section undergoing rigid-body rocking motion. As illustrated by Meisl et al. [15], the components (b) and (c) may not be necessarily in phase with the overall support acceleration (a), which can be a source for wall collapse [15].

The acceleration profile given by the support motion only is given by the sum of the components (a) and (b). The sum of these two components gives a trapezoidal acceleration profile. Denoting with $\ddot{\mathrm{u}}^{\mathrm{T}}(\mathrm{t})$ and $\ddot{\mathrm{u}}^{\mathrm{B}}(\mathrm{t})$ respectively the top and bottom support accelerations, the overall support acceleration results in the average value:

$$
\ddot{\overline{\mathrm{u}}}(\mathrm{t})=\frac{\ddot{\mathrm{u}}^{\mathrm{T}}(\mathrm{t})+\ddot{\mathrm{u}}^{\mathrm{B}}(\mathrm{t})}{2}
$$

The relative support acceleration, which is also a useful parameter in the present work, is defined as:

$$
\ddot{\hat{\mathrm{u}}}(\mathrm{t})=\ddot{\mathrm{u}}^{\mathrm{T}}(\mathrm{t})-\ddot{\mathrm{u}}^{\mathrm{B}}(\mathrm{t})
$$



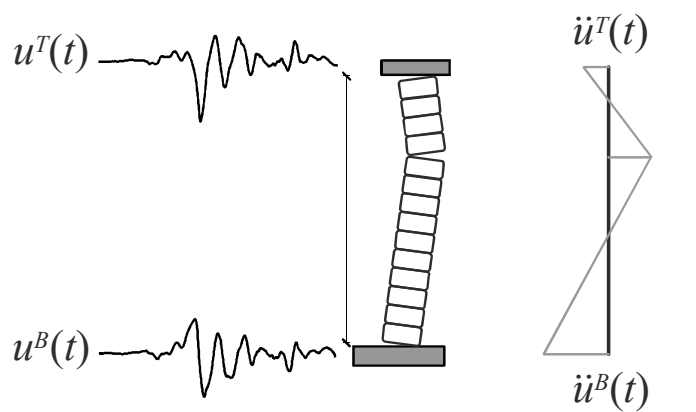

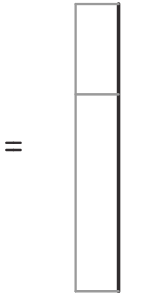

(a)

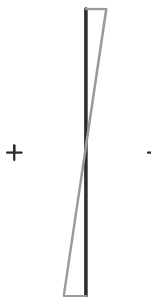

(b)

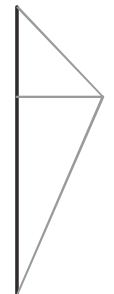

(c)

Figure 1: Acceleration profile components of cracked URM walls subjected to out-of-plane relative top and bottom support motion: (a) component generated by the overall support motion; (b) component provided by the relative motion between the top and bottom supports; (c) component engendered by the inertia forces of the two rocking macro-blocks.

Since in the experimental tests the out-of-plane walls are excited at their base, usually the overall support motion corresponds to the motion applied at the wall base and the diaphragm flexibility is concentrated at the wall top support. In that case, the trapezoidal acceleration profile of the support, i.e. the components (a) $+(b)$ of the acceleration, can experience variation of the acceleration at the top of the wall only [15]. The URM walls tested in this study undergo generic out-of-plane relative support motions where both the top and the bottom supports can move.

\section{WALL MODEL}

$\mathrm{T}$ he numerical model used in this study consists of a discrete element model of an URM wall of unitary length spanning vertically between the top and the bottom supports (Fig. 2). The model is built by means of the commercial software UDEC 6.0 [12] and is the same model previously used and validated by Godio and Beyer [32]. In what follows, the model is briefly recalled. As a novelty, in this study the displacement histories applied to the wall top and bottom supports are different, as illustrated in Fig. 2.

The discrete element model falls within the class of simplified micro-models for masonry, according to which each masonry unit has an effective height $h_{b}$ that is equivalent to the nominal unit height plus the mortar joint thickness (Fig. 2). The numerical model used in this study consists of a $2.8 \mathrm{~m}$-high masonry wall made up of 14 units of effective height $0.2 \mathrm{~m}$ each, laying on a $0.6 \times 0.3 \mathrm{~m}^{2}$ discrete element representing the bottom wall support and in contact with a $0.5 \times 0.1 \mathrm{~m}^{2}$ discrete element representing the top wall support. This top block exerts a permanent, or dead, load of $0.88 \mathrm{kN}$. In addition, a vertical stress $\sigma_{\mathrm{v}}$ is applied to the top support. The axial force, or overburden, $\mathrm{O}$ is the resultant of the vertical stress plus the dead load.

Each masonry unit is modelled as an element of infinite stiffness and strength [12]. The wall deformation is therefore included in the constitutive law used for contact. As in [32], a Coulomb slip model with integration over the contact area is adopted as joint material model [12]. The elastic joint stiffness coefficients are calculated as [10,32]

$$
\mathrm{k}_{\mathrm{n}}=\frac{\mathrm{E}_{\mathrm{m}}}{\mathrm{h}_{\mathrm{b}}} \frac{\mathrm{t}_{\mathrm{w}}}{\mathrm{t}_{\mathrm{w}, \text { eff }}} \quad \mathrm{k}_{\mathrm{s}}=\frac{\mathrm{k}_{\mathrm{n}}}{2(1+\nu)}
$$

where $\mathrm{E}_{\mathrm{m}}$ is the elastic modulus of masonry and $\nu$ is its Poisson's ratio. The joints are also characterised by a tensile strength $\mathrm{f}_{\mathrm{t}}$, a cohesion $\mathrm{c}$, a friction angle $\varphi$, and a dilatation angle $\psi$. The masonry units have rounded corners [12]. Contact between the units consequently occurs over an effective thickness $t_{\mathrm{w}, \text { eff }}$ defined as

$$
\mathrm{t}_{\mathrm{w}, \text { eff }}=\mathrm{t}_{\mathrm{w}}-2 \mathrm{r}_{\mathrm{b}}
$$

with $r_{b}$ the radius of the rounded corner of the units. Contact is discretised in such a way that 10 contact points are placed across the effective wall thickness [32], which enables a realistic simulation of the contact forces exchanged by the blocks during the wall bending and rocking $[35,36]$. The parametric study carried out in this paper aims at studying the influence 


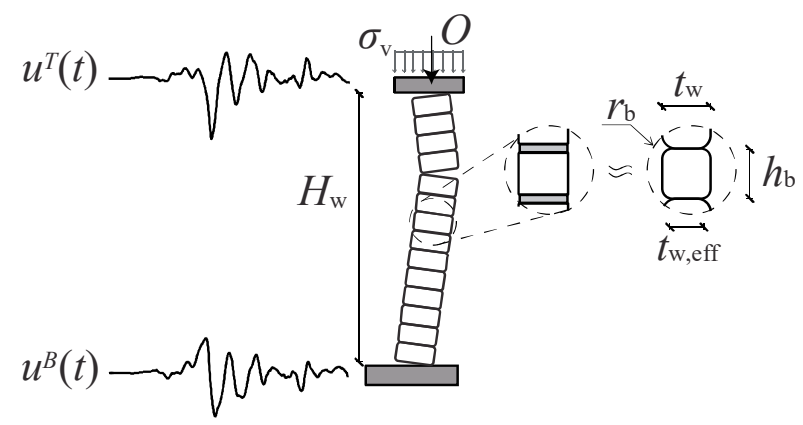

Figure 2: Discrete element model of a vertically-spanning URM wall with different top and bottom support motions used in the study.

on the wall response of the elastic modulus of masonry, the wall height-to-thickness ratio, effective thickness and the vertical stress applied at the wall top. The parameters $\mathrm{E}_{\mathrm{m}}, \mathrm{t}_{\mathrm{w}}, \mathrm{r}_{\mathrm{b}}$ and $\sigma_{\mathrm{v}}$ are therefore changed during the study, as explained later in the paper - see Tab. 2. The other parameters are defined as follows [32]: $\nu=0, \mathrm{f}_{\mathrm{t}}=0 \mathrm{MPa}, \mathrm{c}=2 \mathrm{MPa}, \varphi=35^{\circ}$ and $\psi=0^{\circ}$.

A stiffness-proportional Rayleigh damping model is used in the numerical simulations [12]. Following the strategy validated in [32], the damping centred on the first flexural frequency of the wall, which is also reported in Tab. 2, is obtained considering the wall as a double-clamped Euler's beam:

$$
f_{I}=\frac{1}{2 \pi}\left(\frac{4.730}{H_{w}}\right)^{2} \sqrt{\frac{E_{m}}{\varrho} \frac{I_{w}}{t_{w} L_{w}}}
$$

with $\varrho$ the wall density and $\mathrm{I}_{\mathrm{w}}=1 / 12 \mathrm{~L}_{\mathrm{w}} \mathrm{t}_{\mathrm{w}}{ }^{3}$ the moment of inertia of a generic cross-section of the wall. A damping ratio $\zeta$ of $20 \%$ operates at the above frequency [32].

Time-history analyses are carried out through the numerical model by applying velocity histories in the out-of-plane direction of the wall. The velocity histories that are applied to the top and the bottom wall supports are different and are implemented following the strategies described in the next section.

\section{RELATIVE SUPPORT MOTION GENERATION}

ab. 1 contains the suite of records used in this study. The records are the same as those used by Godio and Beyer [32] and introduced by Sorrentino et al. [37]. The set of selected records covers a wide window of peak ground acceleration (PGA), velocity (PGV) and displacement (PGD), which is thought to diminish the record-to-record variability of the results obtained in the study. Starting from these records, synthetic relative support motions are generated by introducing a phase shift and a relative amplitude.

\section{Generation of support motions with phase shift}

The Hilbert transform is a convenient method for generating signals that have the same amplitude but are phase-shifted, or asynchronous. The Hilbert transform is the integral transform [39]:

$$
\mathcal{H}[\mathrm{s}(\mathrm{t})]=\frac{1}{\pi} \mathrm{PV} \int_{-\infty}^{\infty} \frac{\mathrm{s}(\mathrm{t}-\tau)}{\tau} \mathrm{d} \tau
$$

in which $\mathrm{s}(\mathrm{t})$ is the original signal and PV is the Cauchy principal value of the integral [39]. The Hilbert transform operates on the signal as a filter and allows the analytical signal $z(t)[40]$ to be generated starting from the original one:

$$
z(t)=s(t)+i \mathcal{H}[s(t)]
$$

In this study, the Hilbert transform is used to introduce a phase shift between the input motions of the top and bottom wall supports. Since the numerical model used in this study requires as input the velocity histories at the wall supports, the Hilbert 


\begin{tabular}{lllllllll}
\hline Earthquake & Year & Station & Label* & Mag. & $\begin{array}{l}\text { Duration** } \\
(\mathrm{s})\end{array}$ & $\begin{array}{l}\text { PGA } \\
(\mathrm{g})\end{array}$ & $\begin{array}{l}\text { PGV } \\
(\mathrm{cm} / \mathrm{s})\end{array}$ & $\begin{array}{l}\text { PGD } \\
(\mathrm{cm})\end{array}$ \\
Kern County & 1952 & Taft Lincoln School & TAF111 & 7.36 & 20 & 0.18 & 19 & 9 \\
San Fernando & 1971 & Pacoima Dam (upp. left abut) & PUL164 & 6.61 & 12 & 1.22 & 114 & 39 \\
Friuli & 1976 & Tolmezzo & TMZ000 & 6.5 & 10 & 0.36 & 23 & 5 \\
Imperial Valley & 1979 & Bonds Corner & BCR230 & 6.53 & 15 & 0.78 & 45 & 15 \\
Imperial Valley & 1979 & El Centro (Array \#7) & E07230 & 6.53 & 15 & 0.47 & 113 & 47 \\
Nahanni & 1985 & Site 1 & S1280 & 6.76 & 10 & 1.2 & 41 & 10 \\
Loma Prieta & 1989 & Los Gatos (Lexington Dam) & LEX000 & 6.93 & 10 & 0.44 & 86 & 17 \\
Northridge & 1994 & Rinaldi (Receiving Stat.) & RRS228 & 6.69 & 10 & 0.87 & 148 & 42 \\
Northridge & 1994 & Sylmar (Olive View Med FF) & SYL360 & 6.69 & 10 & 0.84 & 129 & 32 \\
Kobe & 1995 & Takatori & TAK000 & 6.9 & 15 & 0.62 & 121 & 40 \\
\hline *The recori
\end{tabular}

*The records were downloaded from the PEER-NGA database [38]

**The original records were shortened by cutting the parts preceding and succeeding the main shock

Table 1: Natural records used in the parametric study.

transform operates on the input velocities, which are expressed in the following form:

$$
\dot{\mathrm{u}}^{\mathrm{T}}(\mathrm{t})=\frac{(1-\beta)}{2} \dot{\mathrm{u}}(\mathrm{t})+\frac{(1+\beta)}{2} \mathcal{H}[\dot{\mathrm{u}}(\mathrm{t})] \quad \dot{\mathrm{u}}^{\mathrm{B}}(\mathrm{t})=\frac{(1+\beta)}{2} \dot{\mathrm{u}}(\mathrm{t})+\frac{(1-\beta)}{2} \mathcal{H}[\dot{\mathrm{u}}(\mathrm{t})]
$$

with $u(t)$ the original input ground motion considered for the study and $\beta$ a factor enabling to control the phase shift between the support motions. Fig. 3 shows for one of the input ground motions used in this study the displacement histories and the Lissajous diagrams of the top and bottom support displacements resulting from Eqn. (8). In the figure, $\mathrm{u}_{\max }$ is calculated as $\max \{\mathrm{u}(\mathrm{t})\}$. Lissajous is the name used in signal processing to designate diagrams where two signals are plotted on the two axes. This representation is very handy for comparing the two signals. If the signals have equal amplitude and frequency, as in the case of two sinusoidal signals, which are represented by dashed lines in the Lissajous diagrams of Fig. 3, the diagrams will take the shape of an ellipse. The shape and orientation of the ellipse will change according to the phase difference, or phase-shift, between the two signals. As apparent from these diagrams, by using Eqn. (8) for $\beta=0$, the top and bottom support motions are identical and therefore of equal amplitude and in-phase; for non-zero values of $\beta$, the support motions have same amplitude but are out-of-phase with a phase shift that increases as $\beta$ increases: in particular, for $\beta=0.5$ the phase shift amounts to $45^{\circ}$, whereas for $\beta=1$ the support motions are in quadrature, i.e. with a phase shift of $90^{\circ}$. For all values of $\beta$, the overall support velocity, i.e. the average velocity of the top and bottom supports, due to phase shift is (Eqn. (1))

$$
\dot{\overline{\mathrm{u}}}_{\beta}(\mathrm{t})=\frac{\dot{\mathrm{u}}(\mathrm{t})+\mathcal{H}[\dot{\mathrm{u}}(\mathrm{t})]}{2}
$$

and the relative velocity between the top and bottom supports is (Eqn. (2))

$$
\dot{\hat{\mathrm{u}}}_{\beta}(\mathrm{t})=\beta(\mathcal{H}[\dot{\mathrm{u}}(\mathrm{t})]-\dot{\mathrm{u}}(\mathrm{t}))
$$

Generation of support motions with relative amplitude

A relative amplitude is introduced between the top and bottom wall support input motions as follows [10]:

$$
\dot{\mathrm{u}}^{\mathrm{T}}(\mathrm{t})=(1+\alpha) \dot{\mathrm{u}}(\mathrm{t}) \quad \dot{\mathrm{u}}^{\mathrm{B}}(\mathrm{t})=(1-\alpha) \dot{\mathrm{u}}(\mathrm{t})
$$



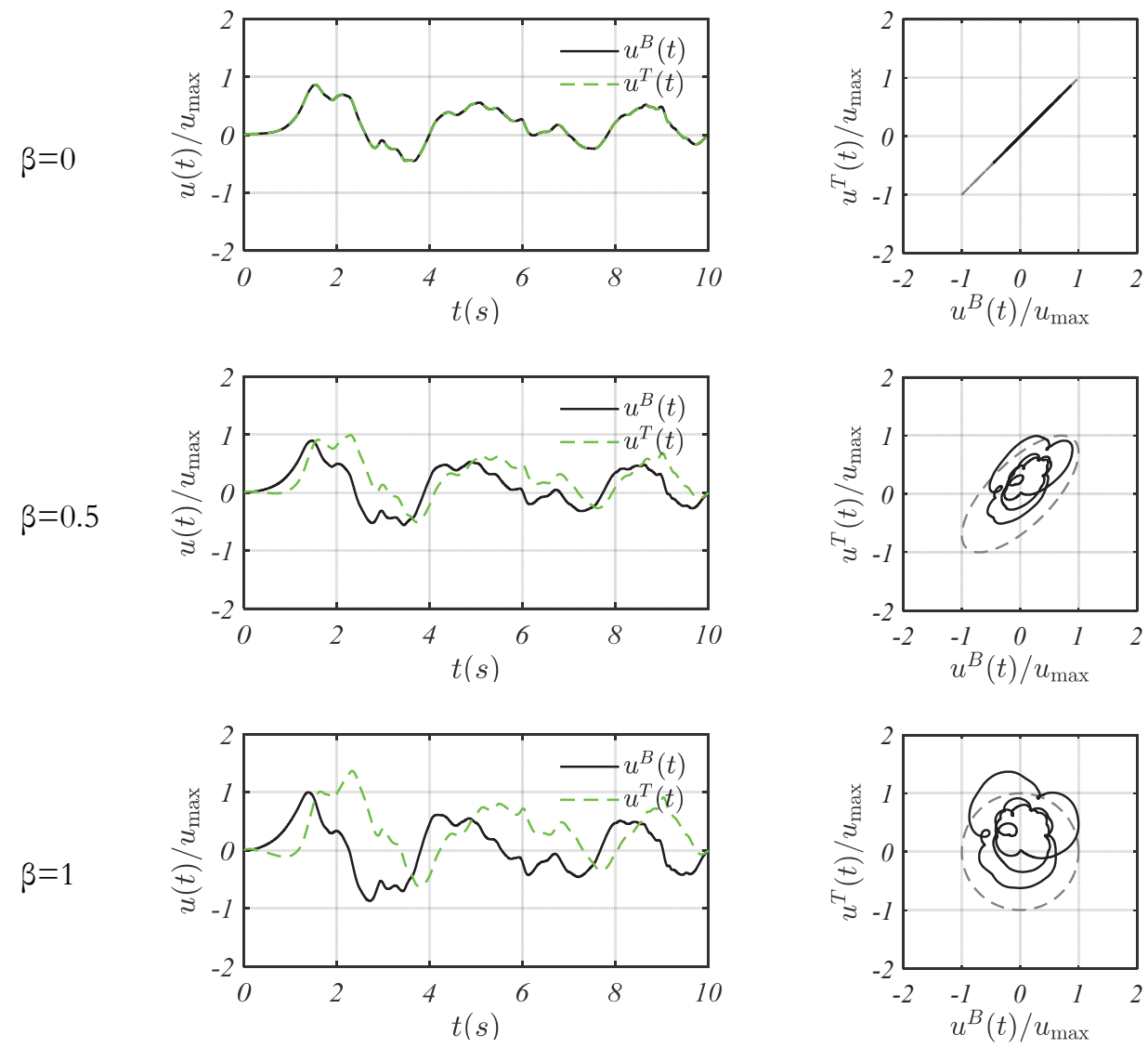

Figure 3: Displacement history (left-hand side) and Lissajous diagrams (right-hand side) of top and bottom wall support motions with phase shift, Eqn. (8) - Nahanni record (Tab. 1). In dashed gray line: equal-amplitude sinusoidal motions shifted of $0^{\circ}$ (top), $45^{\circ}$ (center) and $90^{\circ}$ (bottom).

The input motions generated by the above expressions are synchronous but have unequal amplitude. Starting from Eqn. (11) it is easy to show that for any value of $\alpha$, the overall support velocity is (Eqn. (1))

$$
\dot{\overline{\mathrm{u}}}_{\alpha}(\mathrm{t})=\dot{\mathrm{u}}(\mathrm{t})
$$

and the relative velocity between the top and bottom supports is (Eqn. (2)):

$$
\dot{\hat{\mathrm{u}}}_{\alpha}(\mathrm{t})=2 \alpha \dot{\mathrm{u}}(\mathrm{t})
$$

The factor $\alpha$ controls therefore the difference between the amplitude of the top and bottom support motions. As illustrated in Fig. 4, for $\alpha=0$ the motion of the top and bottom supports are equal and therefore have all the same amplitude than the original input ground motion; for $\alpha=1$ the bottom support is fixed and the top support moves with an amplitude that is twice the amplitude of the original input ground motion; intermediate values of $\alpha$ result in support motions with intermediate relative amplitude. 

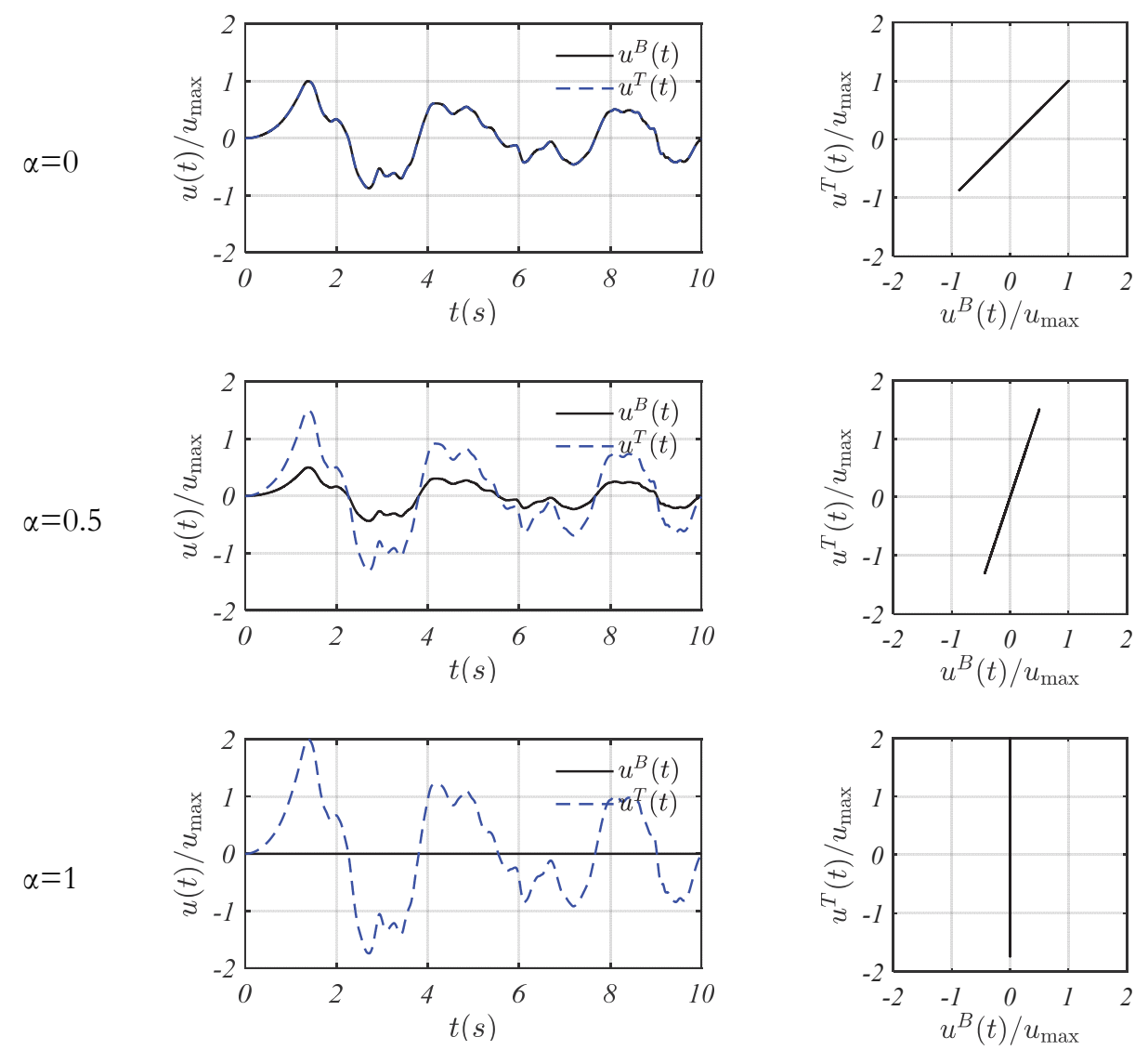

Figure 4: Displacement history (left-hand side) and Lissajous diagrams (right-hand side) of top and bottom wall support motions with relative amplitude, Eqn. (11) - Nahanni record (Tab. 1).

\section{PARAMETRIC STUDY}

A parametric study is carried out on the 16 URM wall configurations already used in [32]. The wall configurations (Tab. 2) are obtained starting from the reference configuration, denoted with $\mathrm{C} 0$, by changing at a time one of the following parameters: in C1-C4, the elastic modulus of masonry $\mathrm{E}_{\mathrm{m}}$; in $\mathrm{C} 5-\mathrm{C} 8$, the wall thickness $\mathrm{t}_{\mathrm{w}}$, determining the height-to-thickness ratio of the wall; in C9-C12, the rounding of the masonry units $\mathrm{r}_{\mathrm{b}}$, determining the effective thickness of the walls; in $\mathrm{C} 13-\mathrm{C} 16$, the vertical stress $\sigma_{\mathrm{v}}$ applied to the top support, giving a different overburden ratio $\mathrm{O} / \mathrm{W}$, where $\mathrm{W}$ is the wall body weight.

In [32], 10 incremental dynamic analyses (IDA) were run for each of the 16+1 configurations, by using the records of Tab. 1. In the present study, 4 sets of $(16+1)$ x 10 IDA are run, resulting in 680 IDA in total. Two sets investigate the dynamic wall response when the top and the bottom support motions have the same amplitude but are phase-shifted; for these 2 sets, Eqn. (8) is used for the generation of the input support motions, with $\beta$ being set to 0.5 and 1 . The other two sets investigate the wall response when the top and the bottom supports are in-phase but have different amplitude; in this case, the support motions are generated by using Eqn. (11) setting $\alpha$ equal to 0.5 and 1 . In the IDA presented in [32], the input support motions were equal, which corresponds here to the case in which either $\beta$ is set to 0 in Eqn. (8) or $\alpha$ is set to 0 in Eqn. (11) (c.f. Fig. 3-Fig. 4). 


\begin{tabular}{llllllll}
\hline Configuration & $\mathrm{t}_{\mathrm{w}}(\mathrm{mm})$ & $\mathrm{H}_{\mathrm{w}} / \mathrm{t}_{\mathrm{w}}(-)$ & $\mathrm{r}_{\mathrm{b}}\left(\% \mathrm{t}_{\mathrm{w}}\right)$ & $\mathrm{t}_{\mathrm{w}, \mathrm{eff}} / \mathrm{t}_{\mathrm{w}}(-)$ & $\mathrm{E}_{\mathrm{m}}(\mathrm{MPa})$ & $\mathrm{O} / \mathrm{W}(-)$ & $\mathrm{f}_{\mathrm{I}}(\mathrm{Hz})$ \\
C0* & 200 & 14 & 2 & 0.96 & 500 & 0.09 & 6.91 \\
$\mathrm{C} 1$ & 200 & 14 & 2 & 0.96 & $\mathbf{1 2 5}$ & 0.09 & 9.77 \\
$\mathrm{C} 2$ & 200 & 14 & 2 & 0.96 & $\mathbf{2 5 0}$ & 0.09 & 19.54 \\
C3 & 200 & 14 & 2 & 0.96 & $\mathbf{1 0 0 0}$ & 0.09 & 27.64 \\
$\mathrm{C} 4$ & 200 & 14 & 2 & 0.96 & $\mathbf{2 0 0 0}$ & 0.09 & 6.91 \\
$\mathrm{C} 5$ & $\mathbf{1 0 0}$ & 28 & 2 & 0.96 & 500 & 0.18 & 13.82 \\
C6 & $\mathbf{1 5 0}$ & 19 & 2 & 0.96 & 500 & 0.12 & 17.28 \\
C7 & $\mathbf{2 5 0}$ & 11 & 2 & 0.96 & 500 & 0.07 & 20.73 \\
C8 & $\mathbf{3 0 0}$ & 9 & 2 & 0.96 & 500 & 0.06 & 13.82 \\
C9 & 200 & 14 & $\mathbf{0 . 5}$ & 0.99 & 500 & 0.09 & 13.82 \\
C10 & 200 & 14 & $\mathbf{1}$ & 0.98 & 500 & 0.09 & 13.82 \\
C11 & 200 & 14 & $\mathbf{1 . 5}$ & 0.97 & 500 & 0.09 & 13.82 \\
C12 & 200 & 14 & $\mathbf{3}$ & 0.94 & 500 & 0.09 & 13.82 \\
C13 & 200 & 14 & 2 & 0.96 & 500 & $\mathbf{1 . 4 0}$ & 13.82 \\
C14 & 200 & 14 & 2 & 0.96 & 500 & $\mathbf{2 . 0 6}$ & 13.82 \\
C15 & 200 & 14 & 2 & 0.96 & 500 & $\mathbf{4 . 0 3}$ & 13.82 \\
C16 & 200 & 14 & 2 & 0.96 & 500 & $\mathbf{6 . 0 1}$ & 13.82 \\
\hline
\end{tabular}

*Reference configuration

Table 2: Walls analysed in the parametric study. Properties in bold are varied with respect to the reference configuration.

\section{RESULTS OF THE STUDY}

\section{Results for support motions with phase shift}

Fig. 5 shows the fragility curves for each of the configurations analysed in the parametric study and for support motions with different phase-shift, i.e. generated by Eqn. (8) for $\beta$ equal to $0,0.5$ and 1 . The fragility curves are built from the results of the IDA, as cumulative distributions of the limit PGA, denoted here as $\mathrm{PGA}_{\lim }$. This latter corresponds to the PGA of the time history in which the wall attains failure for the first time along the IDA and it is defined from Eqn. (9), as the average acceleration of the top and bottom supports:

$$
P G A_{\lim }=\max _{\mathrm{t}}\left|\frac{\ddot{\mathrm{u}}^{\mathrm{T}}(\mathrm{t})+\ddot{\mathrm{u}}^{\mathrm{B}}(\mathrm{t})}{2}\right|=\max _{\mathrm{t}}\left|\ddot{\overline{\mathrm{u}}}_{\beta}\right|
$$

The condition used for wall failure is that the wall undergoes a mid-height displacement $\mathrm{d}$ equal or larger than the limit displacement $\mathrm{d}_{0}$. The probability of wall failure is therefore $P\left(|\mathrm{~d}| \geq \mathrm{d}_{0}\right)$. This displacement is calculated as the maximum displacement that the wall attains under a uniformly distributed lateral load, assuming a failure mechanism similar to the one depicted in Fig. 2, but with fixed wall supports. The expression for $\mathrm{d}_{0}$ is obtained in [41] and, for clarity, is reported here:

$$
\mathrm{d}_{0}=\frac{\mathrm{t}_{\mathrm{w}, \mathrm{eff}}}{2(1-\xi)}
$$

where $\xi$ denotes the position of the middle masonry cracked joint, which can be calculated as: 

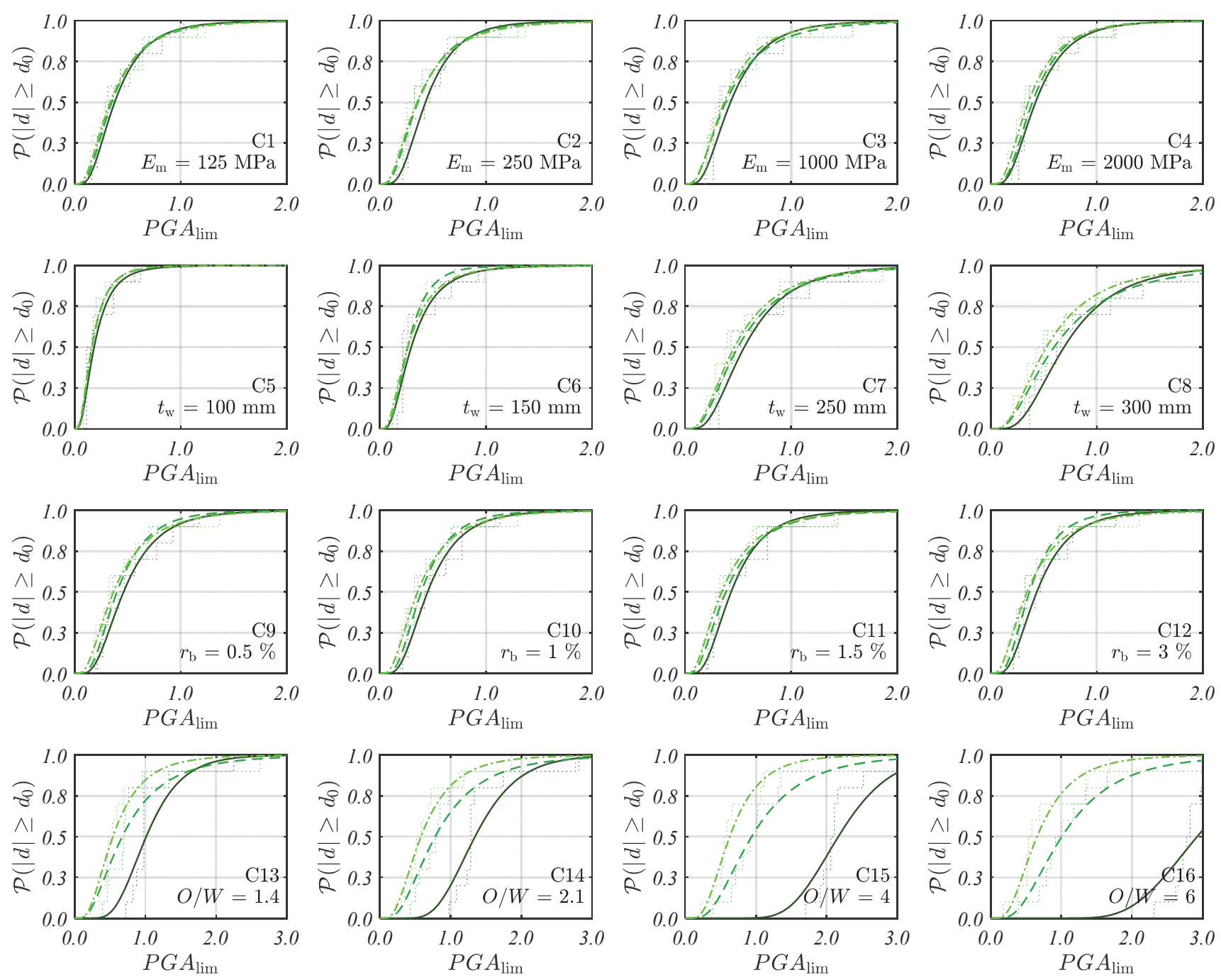

$$
-\beta=0 \quad---\beta=0.5 \quad----\beta=1
$$

Figure 5: Fragility curves based on log-normal distributions obtained from the incremental dynamic analyses (IDA) carried out on URM walls subjected to phase-shifted support motions. For $\beta=0$, in-phase motions; for $\beta=0.5$, motions with phase shift of $45^{\circ}$; for $\beta=1$ : motions with phase shift of $90^{\circ}$. Real discrete distributions based on the set of 10 ground motions are in dotted line and fitted lognormal distributions are in dashed, dashed-dotted or solid lines. PGA values are in units of $g$.

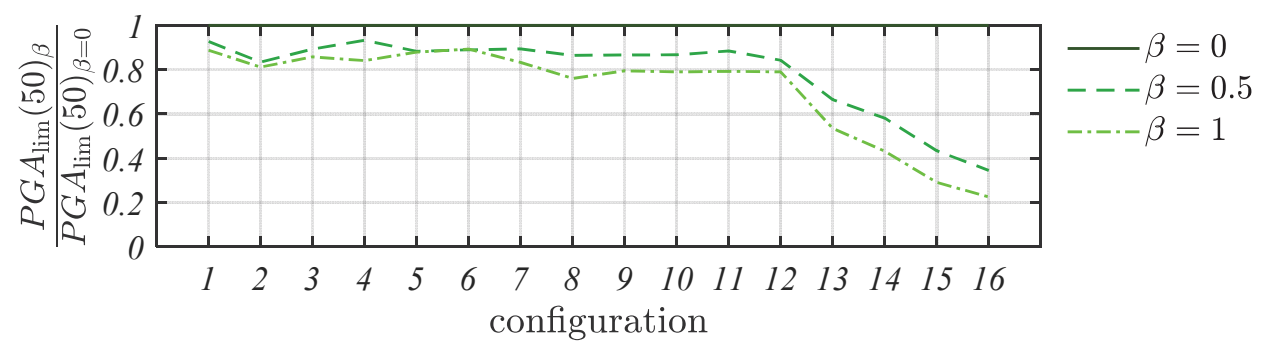

Figure 6: Median values of $\mathrm{PGA}_{\lim }$ for all studied configurations and for different values of $\beta$. 


$$
\xi=\frac{\sqrt{\mathrm{O}(\mathrm{O}+\mathrm{W})}-\mathrm{O}}{\mathrm{W}}
$$

Cases of structural resurrection, i.e. cases where the wall can sustain levels of PGA higher than those leading to collapse for the first time along the IDA [42], have already been observed in rocking masonry structures [43], but are here neglected. As observed in [32], they may occur occasionally but it would be unsafe to consider them in the evaluation of the wall collapse, since from a practical point of view the first onset of failure is of interest.

The figure shows both real distributions, in dotted line, and fitted log-normal distributions, using the line type indicated in the legend. Comparing the curves obtained for all the studied configurations and for a given value of $\beta$, it can be noticed that increasing the wall thickness, which for a fixed wall height comes to decreasing the height-to-thickness ratio (C5-C8), the effective wall thickness over the nominal thickness (C9-C12) and the overburden ratio (C13-C16) increases the acceleration capacity of the wall. On the contrary, changes in the elastic modulus (C1-C4) have almost no effect on the acceleration capacity. An analogous outcome was obtained in [32] for walls subjected to identical support motion.

Comparing the wall capacity for a given configuration and for all values of $\beta$, it appears that increasing $\beta$ from 0 to 1 , i.e. increasing the phase-shift between the top and the bottom wall supports, the fragility curves shift to the left, leading to a decrease of limit PGA for almost all probability levels and configurations. To better quantify the effect of a phase shift in the support motion, the median values $\mathrm{PGA}_{\lim }(50)$ are plotted in Fig. 6 for all configurations and all values of $\beta$. For the configurations $\mathrm{C} 1$ to $\mathrm{C} 12$, a phase-shift between the top and the bottom wall supports engenders a decrease of acceleration capacity of about $10 \%$ with respect to the in-phase case for $\beta=0.5$, which goes up to $20 \%$ when the phase-shift is maximum, i.e. for $\beta=1$. No significant difference between the configurations C1-C4 and C5-C12 is observed. For the configurations $\mathrm{C} 13$ to $\mathrm{C} 16$, the increase of overburden ratio at the wall top leads to a further reduction of the wall capacity. For the configuration $\mathrm{C} 16$, where $\mathrm{O} / \mathrm{W}=6$, the wall capacity is reduced to less than $40 \%$ of its initial value.

The phase-shift of the support motions has therefore a detrimental effect on the wall acceleration capacity. This conclusion is supported by the observation of the wall failure mechanisms: even though the majority of the failure mechanisms is given by the formation of two macro-blocks spanning as illustrated in Fig. 1, for the 34\% and 31\% of the studied configurations and records, deformation patterns corresponding to higher rocking 'modes', i.e. deformation patterns characterized by the formation of more than two macro-blocks, are activated for $\beta=0.5$ and $\beta=1$, respectively. Unfavorable patterns as those discussed in [9], characterized by two macro-blocks rocking in the same direction, are observed for about the $0 \%$ and $3 \%$ of the cases, respectively. It appears, nonetheless, that the P- $\Delta$ effect engendered by the relative support motion due to the phase-shift combined with a relatively high axial load creates the worst-case scenario for the wall.

\section{Results for support motions with relative amplitude}

Fig. 7 shows the fragility curves for each of the configurations analysed in the parametric study and for support motions with relative amplitude, i.e. generated for different values of $\alpha$, namely $0,0.5$ and 1 . The fragility curves are built as for Fig. 5, as cumulative distributions of the limit PGA obtained from the IDA. Fig. 8 sums up the results, by showing the median values of the obtained limit PGA for all configurations and all values of $\alpha$.

Overall, the figures show how introducing relative amplitudes in the wall support motions has a detrimental effect on the wall acceleration capacity. More specifically, for the configurations $\mathrm{C} 1$ to $\mathrm{C} 12$, the relative amplitude between the top and the bottom wall supports engenders a decrease in acceleration capacity with respect to the equal amplitude case of about $10 \%$ for $\alpha=0.5$, and of about $20 \%$ for $\alpha=1$. For the configurations C13 to C16, the decrease in acceleration is much more important and peaks at $85 \%$ for configuration C16 for $\alpha=1$.

From the comparison of these results with those obtained from the first two sets of simulations (Fig. 6), it can be concluded that introducing relative amplitudes in the wall support motions has a detrimental effect on the wall acceleration capacity, which is comparable to the effect of introducing a phase-shift. It appears that the P- $\Delta$ effect engendered by support motions of relative amplitudes combined a relatively high axial load creates the worst-case scenario for the wall. The failure mechanisms activated on the walls are for $16 \%$ and $19 \%$ of the cases, respectively for $\alpha=0.5$ and $=1$, higher 'rocking modes' and for $1 \%$ and $15 \%$ of the cases unfavorable patterns. 

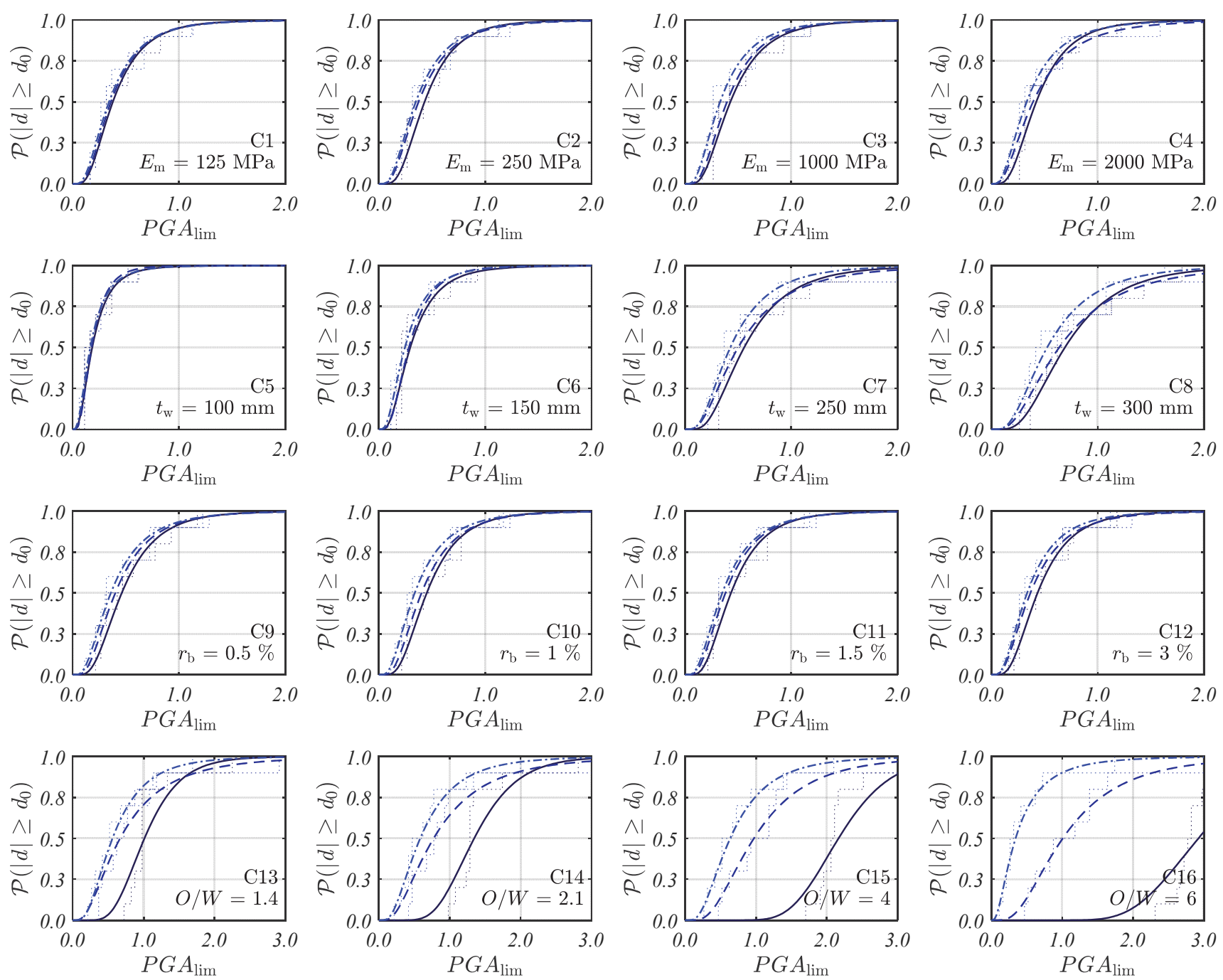

$$
\alpha=0 \quad---\alpha=0.5 \quad-\cdot-\cdot \alpha=1
$$

Figure 7: Fragility curves based on log-normal distributions obtained from the incremental dynamic analyses (IDA) carried out on URM walls subjected to relative-amplitude support motions. For $\alpha=0$, motions of same amplitude; for $\alpha=0.5$, motions with relative amplitude equal to the original input motion; for $\alpha=1$, motions with relative amplitude equal to two times the original input motion and with fixed bottom support. Real discrete distributions based on the set of 10 ground motions are in dotted line and fitted log-normal distributions are in dashed, dashed-dotted or solid lines. PGA values are in units of $\mathrm{g}$.

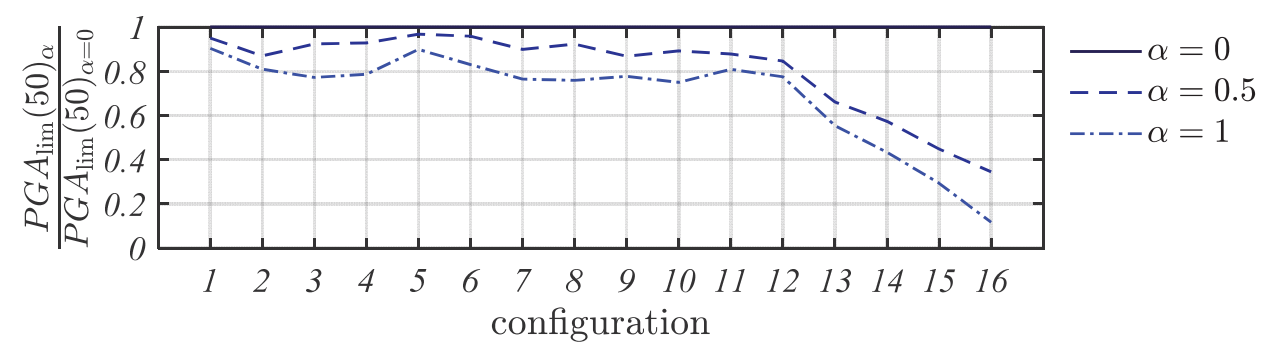

Figure 8: Median values of PGA $A_{\text {lim }}$ for all studied configurations and values of $\alpha$. 


\section{CONCLUSIONS}

his study shows by means of numerical simulations that the acceleration capacity of vertically-spanning URM walls decreases when the walls are subjected to a relative motion between the top and bottom supports. The study quantifies this in a systematic way, by looking at two fundamental input motion characteristics: firstly, by including motions that are phase-shifted, i.e. non-synchronous but of equal amplitude; secondly, through motions that are synchronous but of relative amplitude.

The effect of the phase-shift and relative amplitude of the support motions have been studied for different wall configurations and by a model where the masonry components are modelled with infinite compressive strength and zero tensile strength. The effect of a limited compressive strength can be taken into account in the model by relating it to the effective wall thickness, see e.g. [10]. The assumption of zero tensile strength, which is not always verified in real situations, allows making a comparison with the results of a previous study [32]. As already observed in [32] for walls subjected to equal support motions, it appears here that for a given phase-shift or relative amplitude, variations in the masonry elastic modulus do not have a significant influence on the acceleration capacity of the URM walls. On the other hand, the wall height-to-thickness ratio, the wall effective thickness and, especially, the vertical stress, or overburden, applied at the wall top appear to be critical parameters that should be carefully evaluated because of their influence on the wall capacity [32]. As a novelty, the study further shows that, because of the relative support motion, the acceleration capacity of URM walls can drop by 10 to $20 \%$ for wall configurations with low to moderate overburden ratios and, in cases where the overburden ratio is high, it can drop by more than $50 \%$.

In conclusion, the strategies reported in this study allows quantifying the difference in shift and amplitude between the top and bottom wall support motions in efficient way. The support motions used in this study are nonetheless not yet representative of real building configurations as they do not contain any filtering effect due to the shear walls, which provide the wall supports with an input motion whose main period is close to the fundamental period of the structure [2,33,34]. Further studies characterizing the input motion characteristics, i.e. phase shift and relative amplitude, of consecutive floor motions in URM buildings are necessary to put the present study into a real context and decide whether the extension of existing assessment methods to capture the effect of relative support motions is a step to be envisaged.

\section{REPRODUCIBILITY OF THE ARTICLE CONTENT}

he content of this paper can be reproduced with the files provided at the following permanent repository: https://doi.org/10.5281/zenodo.3187536. The files include outputs of the numerical model, plus Matlab scripts necessary to reproduce Figs. 3-8 presented in the paper.

\section{ACKNOWLEDGMENTS}

he work presented in this paper was funded by the Swiss Federal Office of the Environment and the Construction Department of the Canton Basel-Stadt.

\section{REFERENCES}

[1] Priestley, M.J.N. (1985). Seismic behaviour of unreinforced masonry walls, Bull. New Zeal. Natl. Soc. Earthq. Eng., 18(2), pp. 191-205.

[2] Menon, A., Magenes, G. (2011). Definition of seismic input for out-of-plane response of masonry walls: I. Parametric study, J. Earthq. Eng., 15(2), pp. 165-194, DOI: 10.1080/13632460903494446.

[3] Giongo, I., Dizhur, D., Tomasi, R., Ingham, J.M. (2015). Field testing of flexible timber diaphragms in an existing vintage URM building, J. Struct. Eng., 141(1), pp. d4014009, DOI: 10.1061/(ASCE)ST.1943-541X.0001045.

[4] Brignola, A., Pampanin, S., Podestà, S. (2012). Experimental evaluation of the in-plane stiffness of timber diaphragms, Earthq. Spectra, 28(4), pp. 1687-1709, DOI: 10.1193/1.4000088.

[5] Landi, L., Gabellieri, R., Diotallevi, P.P. (2015). A model for the out-of-plane dynamic analysis of unreinforced masonry 
walls in buildings with flexible diaphragms, Soil Dyn. Earthq. Eng., 79, pp. 211-222, DOI: 10.1016/j.soildyn.2015.09.013.

[6] Penner, O., Elwood, K.J. (2016). Out-of-Plane Dynamic Stability of Unreinforced Masonry Walls in One-Way Bending: Parametric Study and Assessment Guidelines, Earthq. Spectra, 32(3), pp. 1699-1723, DOI: 10.1193/011715EQS011M.

[7] Corporation, M.S. (2000). Working Model 2D.

[8] Sharif, I., Meisl, C.S., Elwood, K.J. (2007). Assessment of ASCE 41 Height-to-Thickness Ratio Limits for URM Walls, Earthq. Spectra, 23(4), pp. 893-908, DOI: 10.1193/1.2790488.

[9] Derakhshan, H., Griffith, M.C., Ingham, J.M. (2015). Out-of-plane seismic response of vertically spanning URM walls connected to flexible diaphragms, Earthq. Eng. Struct. Dyn., DOI: 10.1002/eqe.2671.

[10] Tondelli, M., Beyer, K., DeJong, M. (2016). Influence of boundary conditions on the out-of-plane response of brick masonry walls in buildings with RC slabs, Earthq. Eng. Struct. Dyn., 45(8), pp. 1337-1356, DOI: 10.1002/eqe.2710.

[11] Beyer, K., Tondelli, M., Petry, S., Peloso, S. (2015). Dynamic testing of a four-storey building with reinforced concrete and unreinforced masonry walls: prediction, test results and data set, Bull. Earthq. Eng., 13(10), pp. 3015-3064, DOI: $10.1007 /$ s10518-015-9752-z.

[12] Itasca Consulting Group. (2014). UDEC 6.0.

[13] Griffith, M.C., Magenes, G., Melis, G., Picchi, L. (2003). Evaluation of out-of-plane stability of unreinforced masonry walls subjected to seismic excitation, J. Earthq. Eng., 7(1), pp. 141-169, DOI: 10.1080/13632460309350476.

[14] Griffith, M.C., Lam, N.T.K., Wilson, J.L., Doherty, K. (2004). Experimental Investigation of Unreinforced Brick Masonry Walls in Flexure, J. Struct. Eng., 130(3), pp. 423-432, DOI: 10.1061/(ASCE)0733-9445(2004)130:3(423).

[15] Meisl, C.S., Elwood, K.J., Ventura, C.E. (2007). Shake table tests on the out-of-plane response of unreinforced masonry walls, Can. J. Civ. Eng., 34, pp. 1381-1392, DOI: 10.1139/L07-059.

[16] Penner, O., Elwood, K.J. (2016). Out-of-Plane Dynamic Stability of Unreinforced Masonry Walls in One-Way Bending: Shake Table Testing, Earthq. Spectra, 32(3), pp. 1675-1697, DOI: 10.1193/011415EQS009M.

[17] Psycharis, I.N. (1990). Dynamic behaviour of rocking two-block assemblies, Earthq. Eng. Struct. Dyn., 19(4), pp. 555575, DOI: $10.1002 /$ eqe.4290190407.

[18] Beyer, K., Lucca, F. (2016).Effect of static and kinematic boundary conditions on the out-of-plane response of brick masonry walls. In: Modena, C., da Porto, F., Valluzzi, M.R., (Eds.), Proceedings of the 16th International Brick and Block Masonry Conference, Padova, pp. 1439-1446.

[19] Erwing, R.D., Johnson, A.W., Kariotis, J.C. (1981). Methodology for mitigation of seismic hazards in existing unreinforced masonry buildings: wall testing, out-of-plane. ABK Topical Report 04, El Segundo, California.

[20] Simsir, C., Aschheim, M., Abrams, D. (2004). Out-of-plane dynamic response of unreinforced masonry bearing walls attached to flexible diaphragms, Proc. 13th World Conf. Earthq. Eng..

[21] Avgenakis, E., Psycharis, I.N. (2017). Modeling of Rocking Elastic Flexible Bodies under Static Loading Considering the Nonlinear Stress Distribution at Their Base, J. Struct. Eng., 143(7), pp. 04017051 ,

DOI: $10.1061 /$ (asce)st.1943-541x.0001783.

[22] Pitilakis, K., Tsinidis, G., Karafagka, S. (2017). Analysis of the seismic behavior of classical multi-drum and monolithic columns, Bull. Earthq. Eng., 15(12), pp. 5281-5307, DOI: 10.1007/s10518-017-0160-4.

[23] Kalliontzis, D., Sritharan, S. (2018). Characterizing dynamic decay of motion of free-standing rocking members, Earthq. Spectra, 34(2), pp. 843-866, DOI: 10.1193/011217EQS013M.

[24] de Felice, G. (2011). Out-of-Plane Seismic Capacity of Masonry Depending on Wall Section Morphology, Int. J. Archit. Herit., 5(4-5), pp. 466-482, DOI: 10.1080/15583058.2010.530339.

[25] Stefanou, I., Psycharis, I., Georgopoulos, I.O. (2011). Dynamic response of reinforced masonry columns in classical monuments, Constr. Build. Mater., 25(12), pp. 4325-3437, DOI: 10.1016/j.conbuildmat.2010.12.042.

[26] DeJong, M.J., Vibert, C. (2012). Seismic response of stone masonry spires: Computational and experimental modeling, Eng. Struct., 40, pp. 566-574, DOI: 10.1016/j.engstruct.2012.03.001.

[27] Çakt1, E., Sayg1l1, Ö., Lemos, J. V., Oliveira, C.S. (2016). Discrete element modeling of a scaled masonry structure and its validation, Eng. Struct., 126, pp. 224-236, DOI: 10.1016/j.engstruct.2016.07.044.

[28] Sarhosis, V., Baraldi, D., Lemos, J. V., Milani, G. (2019). Dynamic behaviour of ancient freestanding multi-drum and monolithic columns subjected to horizontal and vertical excitations, Soil Dyn. Earthq. Eng., 120(January), pp. 39-57, DOI: $10.1016 /$ j.soildyn.2019.01.024.

[29] Reuland, Y., Lestuzzi, P., Smith, I.F.C. (2019). A model-based data-interpretation framework for post-earthquake building assessment with scarce measurement data, Soil Dyn. Earthq. Eng., 116(October 2018), pp. 253-263,

DOI: $10.1016 /$ j.soildyn.2018.10.008. 
[30] Malomo, D., Pinho, R., Penna, A. (2019). Applied Element Modelling of the Dynamic Response of a Full-Scale Clay Brick Masonry Building Specimen with Flexible Diaphragms, Int. J. Archit. Herit., 0(0), pp. 1-18, DOI: $10.1080 / 15583058.2019 .1616004$.

[31] Portioli, F., Cascini, L. (2018). Contact Dynamics of Masonry Block Structures Using Mathematical Programming, J. Earthq. Eng., 22(1), pp. 94-125, DOI: 10.1080/13632469.2016.1217801.

[32] Godio, M., Beyer, K. (2019). Evaluation of force-based and displacement-based out-of-plane seismic assessment methods for unreinforced masonry walls through refined model simulations, Earthq. Eng. Struct. Dyn., 48(4), pp. 454 475, DOI: $10.1002 /$ eqe.3144.

[33] Menon, A., Magenes, G. (2011). Definition of seismic input for out-of-plane response of masonry walls: II. Formulation, J. Earthq. Eng., 15(2), pp. 195-213, DOI: 10.1080/13632460903494446.

[34] Abbati, S.D., Cattari, S., Lagomarsino, S. (2019). Seismic Assessment of Single-Block Rocking Elements in Masonry Structures, Mason. Int., 31(2), pp. 39-48.

[35] Godio, M., Stefanou, I., Sab, K. (2018). Effects of the dilatancy of joints and of the size of the building blocks on the mechanical behavior of masonry structures, Meccanica, 53(7), pp. 1629-1643, DOI: 10.1007/s11012-017-0688-z.

[36] Lemos, J. V. (2017). Contact representation in rigid block models of masonry, Int. J. Mason. Res. Innov., 2(4), pp. 321334.

[37] Sorrentino, L., Masiani, R., Decanini, L.D. (2006). Overturning of rocking rigid bodies under transient ground motions, Struct. Eng. Mech., 22(3), pp. 293-310, DOI: 10.12989/sem.2006.22.3.293.

[38] Pacific Earthquake Engineering Research Center. Pacific Earthquake Engineering Research Center.(2017). PEER Ground Motion Database. Available at: https://ngawest2.berkeley.edu. [accessed September 20, 2016].

[39] Oppenheim, A. V., Schafer, R.W. (1999). Discrete Time Signal Processing, New Jersey, Prentice-Hall.

[40] Gabor, D. (1946). Theory of communication. Part 1: The analysis of information, J. Inst. Electr. Eng. - Part III Radio Commun. Eng., 93(26), pp. 429-441, DOI: 10.1049/ji-3-2.1946.0074.

[41] Godio, M., Beyer, K. (2019). Tri-linear model for the out-of-plane seismic assessment of vertically-spanning unreinforced masonry walls, J. Struct. Eng., accepted, pp. 1-9, DOI: 10.1061/(ASCE)ST.1943-541X.0002443.

[42] Vamvatsikos, D., Allin Cornell, C. (2002). Incremental dynamic analysis, Earthq. Eng. Struct. Dyn., 31(3), pp. 491-514, DOI: 10.1002/eqe.141.

[43] Psycharis, I.N. (2018).Seismic Vulnerability of Classical Monuments. Recent Advances in Earthquake Engineering in Europe. ECEE 2018. Geotechnical, Geological and Earthquake Engineering, pp. 563-582. 